Clemson University

TigerPrints

$9-2020$

\title{
Investigating Hierarchical Effects of Adaptive Signal Control \\ System on Crash Severity using Random-parameter Ordered \\ Regression Models Incorporating Observed Heterogeneity
}

\author{
Weimin Jin \\ Clemson University,weiminj@g.clemson.edu \\ Mashrur Chowdhury \\ Clemson University, mac@clemson.edu \\ M. Sabbir Salek \\ Clemson University, msalek@clemson.edu \\ Sakib Mahmud Khan \\ University of California - Berkeley, sakibk@berkeley.edu \\ Patrick Gerard \\ Clemson University, pgerard@clemson.edu
}

Follow this and additional works at: https://tigerprints.clemson.edu/civileng_pubs

Part of the Civil and Environmental Engineering Commons

\section{Recommended Citation}

Please use the publisher's recommended citation. https://www.sciencedirect.com/science/article/pii/ S0001457520303183

This Article is brought to you for free and open access by the Glenn Department of Civil Engineering at TigerPrints. It has been accepted for inclusion in Publications by an authorized administrator of TigerPrints. For more information, please contact kokeefe@clemson.edu. 


\section{Investigating Hierarchical Effects of Adaptive Signal Control System on Crash Severity}

2 using Random-parameter Ordered Regression Models Incorporating Observed

3 Heterogeneity

4

5 Weimin Jin ${ }^{1 *}$, Mashrur Chowdhury ${ }^{2}$, M Sabbir Salek $^{3}$, Sakib Mahmud Khan ${ }^{4}$, and Patrick Gerard ${ }^{5}$

6

$7 \quad{ }^{1}$ Glenn Department of Civil Engineering, Clemson University, Clemson, SC, 29634, USA;

$8 \quad$ email: weiminj@g.clemson.edu

9

$10{ }^{2}$ Ph.D., Professor, Glenn Department of Civil Engineering, Clemson University, Clemson, SC,

11 29634, USA; email: mac@ clemson.edu

12

$13{ }^{3}$ Glenn Department of Civil Engineering, Clemson University, Clemson, SC, 29634, USA;

14 email: $\underline{\text { msalek@clemson.edu }}$

15

$16{ }^{4}$ Ph.D., Postdoctoral Scholar, Institute of Transportation Studies, U.C. Berkeley 94720, USA;

17 email: $\underline{\text { sakibk@ berkeley.edu }}$

$19{ }^{5}$ Ph.D., Professor, School of Mathematical and Statistical Sciences, Clemson University,

20 Clemson, SC, 29634, USA; email: pgerard@ clemson.edu

$22 *$ Corresponding author. 
27 By handling conflicting traffic movements and establishing dynamic coordination between 28 intersections in real-time, the Adaptive Signal Control System (ASCS) can potentially improve 29 the operation and safety of signalized intersections on a corridor. This study identifies the 30 hierarchical effects of ASCS on the crash severity by exploring the heterogeneous effect of 31 ASCS on the crash severity. Four different random-parameter ordered regression models (two 32 ordered probit models, and two ordered logit models) are developed and compared. The analysis 33 reveals that the random-parameter ordered probit and logit models (ROP and ROL) with 34 observed heterogeneity perform better than the random-parameter ordered probit and logit 35 models (RP and RL) without observed heterogeneity in terms of the Akaike information criteria 36 and the goodness of fit of the model. The ROP model performs better than the ROL model in

37 terms of classification model performance measures. The ROP model enables parameters (i.e., 38 the coefficients of the explanatory variables) to vary as a function of explanatory variables as 39 well as across observations, thus accounting for both observed (captured by available 40 explanatory variables) and unobserved (not captured by available explanatory variables)

41 heterogeneity. The analysis reveals that the presence of ASCS is associated with lower crash

42 severity. In this study, observed heterogeneity of ASCS effects on the crash severity is captured 43 by variables related to the intersection and corridor features. Other contributing factors besides 44 ASCS, such as annual average daily traffic, speed limit, lighting, peak period, crash type (rear45 end, angle), and pedestrian involvements, are also associated with the probability of crash 46 severity. Unobserved heterogeneity of the effect of angle crash type on the crash severity is

47 found to exist across the observations. The findings of this research have practical implications 
48 for establishing ASCS implementation guidelines in lowering the probability of higher crash

49 severity.

51 Keywords: Adaptive Signal Control System, Safety, Crash Severity, Ordered Regression Model,

52 Unobserved and Observed Heterogeneity

\section{$53 \quad 1$ Introduction}

54 According to the American Association of State Highway and Transportation Officials

55 (AASHTO) Strategic Highway Safety Plan (Antonucci et al., 2004), intersection-related crashes

56 make up about 23 percent of all fatal crashes. Improving safety at intersections has become one

57 of 22 key areas of focus in this plan. Through traffic control and operational improvement

58 strategies, this plan aims at lowering crash severity and decreasing crash frequency at signalized

59 intersections. Transportation agencies have been seeking new insights and approaches to

60 improve safety at signalized intersections.

61

62 Adaptive Signal Control System (ASCS) is an advanced signal control system deployed at

63 intersections. Although each type of ASCS is unique, all types of ASCS use a similar framework

64 to meet fluctuating real-time traffic demand. ASCS usually includes algorithms that optimize and

65 update parameters (i.e., cycle length, offsets, phase splits, and phase sequence) of traffic signals

66 in real-time (Gartner et al., 2002; Lowrie, 1990). ASCS requires detectors such as loop detectors

67 and video detectors, and a communication network enabling the central and/or local controllers

68 to communicate with such detectors. Prior to the deployment of ASCS, conventional signal

69 systems (i.e., pre-timed or actuated signal control) based on Time of Day (TOD) are typically 
70 used at signalized intersections. These TOD based signal systems with pre-set signal plans

71 usually updated every two to three years cannot handle highly variable traffic demand. However,

72 ASCS can better accommodate fluctuating traffic demand or extreme traffic conditions. Previous

73 studies suggest that ASCS has produced significant operational improvements on corridors and

74 at intersections (Eghtedari, 2006; Elkins and Niehus, 2012; Fontaine et al., 2015; Kergaye et al.,

75 2009; Khattak, 2016; Khattak et al., 2019b; So et al., 2014). By handling conflicting traffic

76 movements and establishing dynamic coordination between intersections in real-time, ASCS can

77 smooth traffic flow and reduce traffic congestion, thus potentially yielding safety benefits for

78 signalized intersections (Dutta et al., 2010; Fink et al., 2016; Jin et al., 2019; Khattak et al., 2018;

79 Ma et al., 2016). These studies related to the safety effects of ASCS have emphasized the impact

80 of ASCS on the crash frequency but not its effect on the outcomes of crash severity (i.e., non-

81 injury, possible injury, non-incapacitating injury, incapacitating injury, or fatal).

83 Only a few previous studies have examined ASCS effects on crash severity outcomes. Out of

84 those studies, two studies (Dutta et al., 2010; Fink et al., 2016) assume that the ASCS effects on

85 crash severity are fixed in all signalized intersections for a certain type of ASCS. One recent

86 study (Khattak et al., 2019a) has identified the disparity of ASCS effects on crash severity with

87 two different types of ASCS and the difference of ASCS effects on crash severity between two

88 states- Pennsylvania and Virginia. However, previous studies typically assume that ASCS effects

89 on crash severity outcomes do not vary across observations (i.e., crashes).

90

91 Crash severity outcomes could be associated with a series of variables related to the corridor,

92 intersection, and crash features. A multilevel structure (i.e., hierarchical structure) inherent in the 
93 crash data will be overlooked if all the variables are viewed at one level. Hierarchical modeling

94 is used to represent the multilevel-structure of the crash data. The hierarchical effect on crash

95 estimation has been explored in previous studies (Chen and Persaud, 2014; Huang et al., 2008;

96 Khazraee et al., 2018; Krishnan et al., 2013; Xie et al., 2013). In this study, ASCS is usually

97 deployed at several signalized intersections on corridors; thus, the hierarchical structure exists

98 inherently in the crash data. The crash data structure can be viewed as a two-level hierarchy with

99 Level 1 being an individual crash, and Level 2 being the intersection and corridor (i.e., one

100 individual crash can be associated with one specific intersection and corridor). The ASCS effect

101 on the crash severity that exists in the hierarchical structure can be estimated by implementing

102 hierarchical models. A random-parameter ordered regression model integrating observed

103 heterogeneity (also known as a hierarchical model) allows the ASCS parameter to vary both as a

104 function of explanatory variables related to the intersection and corridor features, and across

105 crashes. This kind of ASCS effect that exists in the hierarchical structure is referred to as

106 "Hierarchical Effects of ASCS on the Crash Severity" in this paper.

108 In previous studies related to crash severity outcome modeling, random-parameter ordered 109 regression models have been implemented, but they have not been integrated with observed 110 heterogeneity. This study contributes to the literature related to ASCS effects on crash severity 111 by developing random-parameter ordered regression models with observed heterogeneity. Our 112 model is capable of accounting for both observed (i.e., changes in the effect of predictors across

113 the observations that are known and could be captured by available explanatory variables) and 114 unobserved (i.e., changes in the effect of predictors across the observations that are unknown and 115 could not be captured by available explanatory variables) heterogeneity. The objective of this 
116 paper is to determine the hierarchical effects of ASCS on the crash severity. Through accounting

117 for the observed heterogeneity in random-parameter ordered regression models using crash data

118 from six ASCS corridors with 65 signalized intersections, the hierarchical effects of ASCS on

119 the crash severity are identified. The identification of the hierarchical effects of ASCS on the

120 crash severity provides several practical implications on ASCS implementations at the standpoint

121 of safety. The same ASCS type has been deployed at the intersections considered in this study.

122 So, the algorithms of this particular type of ASCS are the same for all the intersections

123 considered in this study. ASCS optimizes the cycle length, phase splits, and offsets in real-time

124 based on current traffic conditions to minimize overall traffic delays at the intersections while

125 guaranteeing a reasonable coordination between the intersections on a corridor. Our study

126 focuses on investigating the effects of a particular ASCS type (which this paper refers to as

127 "ASCS") on the cash severity without considering the variations between multiple ASCS types

128 as it is not within the scope of this study.

130 The remainder of the paper is organized as follows: literature review, research method, data 131 description, results and analysis, and conclusions. The literature review section entails the safety 132 effects of the ASCS on the crash frequency, the crash severity outcomes associated with ASCS, 133 and models developed for the crash severity outcomes. A discussion of the ordered regression 134 models and model implementation are included in the research method section. The data 135 description details the description of variables contributing to the crash severity. The model 136 comparison and estimation results on the association between contributing factors and crash 137 severity are detailed in the results and analysis section. Finally, the summary findings and 138 practical implications are detailed in the conclusions section. 
$140 \quad 2.1$ Safety effects of adaptive signal control systems on crash frequency

141 As ASCS uses real-time traffic data to maximize vehicle progression and reduce vehicle stops, it

142 is expected to improve safety by reducing rear-end crash probability compared to pre-timed or

143 actuated signal control systems. Based on multiple evaluations across the nation, ASCS has been

144 found to improve intersection safety, with a few exceptions. In one study conducted in Virginia,

145 Fontaine et al. (Fontaine et al., 2015) note that a $17 \%$ reduction in the total number of crashes is

146 associated with ASCS using the Empirical Bayes (EB) method. In Pennsylvania, Khattak

147 (Khattak, 2016) notes that $34 \%$ and $45 \%$ reductions in the total number of crashes and fatal and

148 injury crashes are associated with ASCS, respectively. Based on the analysis of ten years of 149 crash data (1999 - 2008) in Michigan, ASCS is found to reduce the total crash rate by 6\% (Dutta 150 et al., 2010). Fink et al. (Fink et al., 2016) have examined the safety effects of signalized 151 intersections with Sydney Coordinated Adaptive Traffic System (SCATS), an ASCS type, in 152 Michigan. Fink et al. (Fink et al., 2016) have implemented a cross-sectional method by using 498 153 signalized intersections and found that a $19.3 \%$ reduction in angle crashes is associated with 154 SCATS.

\subsection{Safety effects of adaptive signal control systems on crash severity outcomes}

156 Evaluation of the impact of ASCS deployment on crash severity outcomes is predominantly 157 absent from the literature. Only a few studies related to crash severity effects of ASCS are 158 identified. Dutta et al. (Dutta et al., 2010) have used before period (1999 - 2001) and after period 159 (2003 - 2008) crash data from one corridor with SCATS and another with the pre-timed signal. 160 They perform a $t$-test analysis and find that a definite change in severity from incapacitating 
161 injury and non-incapacitating injury to possible injury. But, the $t$-test fails to prove the

162 superiority of SCATS over the pre-timed signal control system in lowering the crash severity at a

1630.05 significance level.

164

165 In their analysis, Fink et al. (Fink et al., 2016) have used data from 498 signalized intersections

166 in Michigan. They have found that a statistically significant reduction in non-incapacitating

167 injuries is associated with SCATS deployment. However, they have not found that a statistically

168 significant reduction in fatal and incapacitating injuries is associated with SCATS.

169

170 Similarly, in the examination of the effect of ASCS on the crash severity, Khattak et al. (Khattak

171 et al., 2019a) have identified the disparity between two different types of ASCS and between two

172 states- Pennsylvania and Virginia. They have found that both types of ASCS are associated with

173 lower crash severity, and ASCS implemented in these two states are also associated with lower

174 crash severity.

\section{$1752.3 \quad$ Modeling of crash severity outcomes}

176 Of the various modeling approaches developed for modeling the crash severity outcomes, the

177 most widely used models are ordered regression models (i.e., ordered probit and logit models),

178 which account for the ordinal nature reflected in crash severity levels.

180 Khattak and Tung (Khattak and Tung, 2015) have used an ordered probit model to quantify the

181 impact of various contributing factors (e.g., train speed, weather condition, area types, etc.) on

182 three different severity levels (i.e., no injury, injury, and fatal) of pedestrian injuries. Zhao and

183 Khattak (Zhao and Khattak, 2015) have used an ordered probit model to investigate contributing 
184 factors (e.g., the involvement of freight trains, older drivers, high train speeds, high vehicle

185 speeds, and female drivers) correlated with crash severity levels of motorists in the case of the

186 train-vehicle crashes. Eluru et al. (Eluru et al., 2012) have used a latent segmentation based

187 ordered logit model to identify the contributing factors (e.g., time of the collision, motorist age,

188 snow and/or rain condition, the presence of a vehicle struck by a train, and driver operation in the

189 pre-crash) that influence injury severity of vehicle drivers in train-motor crashes at highway-

190 railway grade crossings. In some studies, researchers have not considered crash severity levels as

191 ordinal outcomes and therefore used multinomial logit models (Fan et al., 2015; Fink et al.,

192 2016). Based on a comparative analysis of the three most common models (i.e., ordered probit,

193 mixed logit model, and multinomial logit), Ye, and Lord (Ye and Lord, 2014) have concluded

194 that each can be the best choice based on the sample size requirement. Among the three models, 195 the mixed logit model requires the largest sample size, and the multinomial logit model requires 196 the second-largest sample size. In contrast, the ordered probit model requires the smallest sample 197 size. The minimum sample size recommended by (Ye and Lord, 2014) for the mixed logit 198 model, multinomial logit model, and ordered probit models is 5000, 2000, and 1000, 199 respectively.

\section{Research method}

201 Ordered regression models (i.e., ordered probit and logit models) are implemented to account for

202 the ordinal nature (e.g., ranging from non-injury to possible injury, to non-incapacitating injury, 203 to incapacitating injury, to fatal) of crash severity. The ordered regression models have been 204 widely used to consider the ordinal nature of crash data mainly. However, an underlying 205 assumption of ordered regression models is that the estimated parameters across crash severity 
206 levels are constant. This assumption is referred to as "the proportional odds or parallel 207 regression" assumption. In this study, the authors initially fit ordered regression models and test 208 this possible assumption by using the Brant test (Brant, 1990). It is found that the variable 209 associated with the presence of ASCS does not violate the assumption. However, ordered 210 regression models cannot capture unobserved heterogeneity across observations. Thus, the

211 models may result in incorrect estimates (Washington et al., 2020). The random-parameter 212 ordered regression model enables the parameters to vary across observations and has been 213 explored by previous studies (Dabbour et al., 2017; Jalayer et al., 2018; Khattak et al., 2019a).

214 However, in previous studies related to crash severity outcome modeling, random-parameter 215 ordered regression models have not been integrated with observed heterogeneity.

\section{$2163.1 \quad$ Random-parameter ordered regression model}

217 The random-parameter ordered regression models (Greene, 2003) are implemented in this paper.

218 The ordered regression model is used to study the following latent process:

$$
y_{i}^{*}=\mathbf{X}_{i} \boldsymbol{\beta}_{i}+\varepsilon_{i}, \quad i=1, \ldots, n
$$

$$
\boldsymbol{\beta}_{i} \sim g\left(\boldsymbol{\beta}_{i} \mid \boldsymbol{\theta}\right)
$$

221 where $y_{i}^{*}$ is a latent variable for the observation (i.e., crash) $i ; \mathbf{X}_{i}$ is a vector of the explanatory

222 variables; $\boldsymbol{\beta}_{i}$ is a vector of the coefficients; $\varepsilon_{i}$ is the error term; $n$ is the total number of 223 observations. 
225 In Eq. (1) and (2), $\boldsymbol{\beta}_{i}$ is allowed to be different for each observation $i$ rather than fixed for all

226 observations. The distribution $g\left(\boldsymbol{\beta}_{i} \mid \boldsymbol{\theta}\right)$ is specified to enable $\boldsymbol{\beta}_{i}$ vary across observations, where

$227 \boldsymbol{\theta}$ is a vector of the mean and variance of the random distribution.

228

$229 \boldsymbol{\beta}_{i}$ can be written as $\boldsymbol{\beta}_{i}=\boldsymbol{\beta}+\mathbf{L} \boldsymbol{\omega}_{i}$, where $\boldsymbol{\beta}$ is the vector of the mean of the coefficients. Each

230 coefficient $\beta_{k i}$ can be expressed as $\beta_{k i}=\beta_{k}+\sigma_{k} \omega_{k i} . \beta_{k i}$ is the $k^{\text {th }}$ element in $\boldsymbol{\beta}_{i} . \boldsymbol{\omega}_{i}$ is a vector

231 of random variables that follow a random distribution. $\omega_{k i}$ is the $k^{\text {th }}$ element in $\boldsymbol{\omega}_{i}$. $\omega_{k i}$ has a

232 specific random distribution such as normal distribution and uniform distribution. $\mathbf{L}$ is a diagonal

233 matrix of the standard deviations of the coefficients, $\sigma_{k}$. The unobserved heterogeneity is

234 represented by $\sigma_{k}$. $\beta_{k i}$ has a specific random distribution such as normal distribution and

235 uniform distribution. For example, $\beta_{k i}$ follows a normal distribution with a mean of $\beta_{k}$ and a

236 variance of $\sigma_{k}^{2}$ when $\omega_{i} \sim N(0,1)$.

237

238 The probability of the crash severity level $j$ for the crash $i$, can be calculated as:

$$
p\left(y_{i}=j\right)=P\left(\mu_{j-1}<\mathrm{y}_{i}^{*} \leq \mu_{j}\right)=F\left(\mu_{j}-\mathbf{X}_{\mathbf{i}} \boldsymbol{\beta}_{i}\right)-F\left(\mu_{j-1}-\mathbf{X}_{\mathbf{i}} \boldsymbol{\beta}_{i}\right)
$$

240 where $y_{i}$ is an ordered categorical variable, $\mu_{j}$ is the $j^{\text {th }}$ threshold in the model, and $F$ is the

241 standard normal Cumulative Distribution Function (CDF) for the ordered probit model or logistic

242 CDF for the ordered logit model. 
244 "KABCO” injury scale (K- fatal; A- incapacitating injury; B- non-incapacitating injury; C245 possible injury; O- no injury) is usually used for classifying injuries. The crash severity levels 246 provided by the South Carolina Department of Transportation (SCDOT) crash database include

247 five categories: non-injury, possible injury, non-incapacitating injury, incapacitating injury, and 248 fatal, which correlates to the KABCO injury scale. Since relatively fewer crashes $(1.08 \%$ out of 249 observations) are reported for incapacitating injury (i.e., A) and fatal (i.e., K) categories in this 250 study, the two categories are combined with the non-incapacitating injury (i.e., B) category. The $251 \mathrm{KAB}$ represents a sum of $\mathrm{K}, \mathrm{A}$, and $\mathrm{B}$ injury crashes, which is typically evaluated in safety 252 studies (National Research Council (US)., 2010). The crash severity levels are coded as three 253 categories in this paper: (1) non-injury (i.e., O), (2) possible injury (i.e., C), and (3) non254 incapacitating injury, incapacitating injury and fatal combined (i.e., KAB).

256 The authors use the following model to express the response variable, $y_{i}$ which is composed of 257 three crash severity levels. It is expressed as

$$
\begin{gathered}
y_{i}=0 \text { if } y_{i}^{*} \leq \mu_{0} \\
y_{i}=1 \text { if } \mu_{0}<y_{i}^{*} \leq \mu_{1} \\
y_{i}=2 \text { if } y_{i}^{*}>\mu_{1}
\end{gathered}
$$

261 where, $y_{i}=0$ indicates that the crash is $\mathrm{O}\left(\mathrm{KABCO}\right.$ scale); $y_{i}=1$ indicates that the crash is $\mathrm{C}$

262 (KABCO scale); $y_{i}=2$ indicates that the crash is $\mathrm{K}, \mathrm{A}$ or $\mathrm{B}$ (KABCO scale); $\mu_{0}$ and $\mu_{1}$

263 represent different thresholds for three crash severity levels; $\mu_{0}$ is 0 here for non-injury. Here,

264 only one threshold (i.e., $\mu_{1}$ ) needs to be estimated. 


\subsection{Random-parameter ordered regression model with observed heterogeneity}

266 The random-parameter ordered regression model with observed heterogeneity can accommodate

267 observed heterogeneity by allowing parameter variations to be captured by available explanatory

268 variables. This model is also referred to as a hierarchical model (Greene and Hensher, 2010;

269 Sarrias, 2016).

271 The hierarchical model is used to represent the multilevel-structure of the crash data. In the study

272 corridors considered in this research, ASCS is usually deployed at several signalized

273 intersections along corridors, thus the hierarchical structure exists inherently in the crash data. As

274 shown in Figure 1, each crash can be associated with one specific intersection that belongs to

275 one specific corridor. The crash data structure can be viewed as a two-level hierarchy with Level

2761 being an individual crash, and Level 2 being the intersection and corridor that include the

277 individual crash. The intersection and corridor are considered at the same level in the model.

278 Also, the two-level hierarchy model is considered to avoid excessive complexity of the model

279 development. The ASCS effect on the crash severity that exists in the hierarchical structure can

280 be estimated by implementing the hierarchical model.

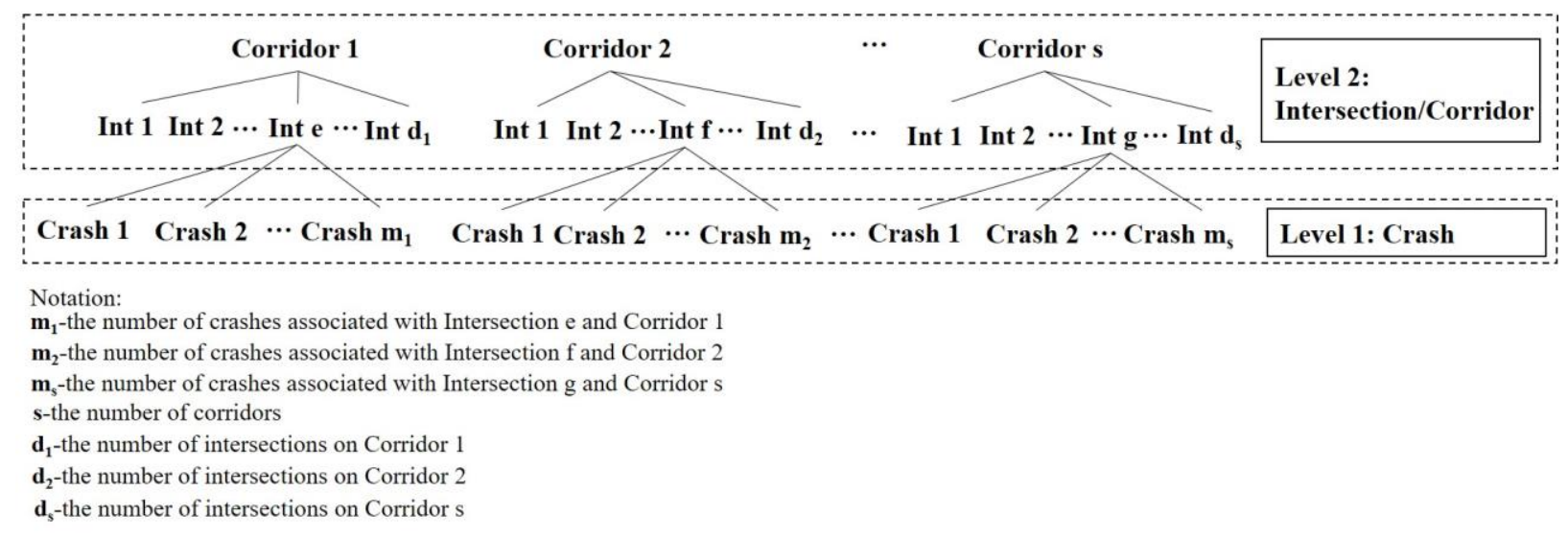


284 In the crash level (Level 1 in the hierarchical model), $y_{i}^{*}$ is used to study the latent process as 285 shown below:

$286 \quad y_{i}^{*}=\mathbf{X}_{i} \boldsymbol{\beta}_{i}+\varepsilon_{i}, \quad i=1, \ldots, n$

287 where, $\mathbf{X}_{i}$ is a vector of the crash-level explanatory variables for the $i^{\text {th }}$ observation; $\boldsymbol{\beta}_{i}$ is a 288 vector of the coefficients; $\varepsilon_{i}$ is the error term; $n$ is the total number of observations.

290 In the intersection/corridor level (Level 2 in the hierarchical model), $\boldsymbol{\beta}_{i}$ is specified by Eq. (8).

291 The specification of Eq. (8) allows the coefficients to vary with different intersections and 292 corridors.

$293 \boldsymbol{\beta}_{i}=\boldsymbol{\beta}+\boldsymbol{\Pi} \mathbf{s}_{i}+\mathbf{L} \boldsymbol{\omega}_{i}$

294 where, $\boldsymbol{\beta}$ is a vector of the mean of coefficients; $\boldsymbol{\omega}_{i}$ is a vector of random variables that follow 295 random distributions; $\mathbf{L}$ is a diagonal matrix of the standard deviations of the coefficients; $\mathbf{s}_{i}$ is a 296 vector of intersection/corridor-level explanatory variables; $\Pi$ is a matrix of coefficients of the 297 intersection and corridor related variables. Then, the expectation of coefficients is $298 E\left(\boldsymbol{\beta}_{i}\right)=\boldsymbol{\beta}+\boldsymbol{\Pi} \mathbf{s}_{i}$. The expectation of coefficients is a function of the intersection/corridor-level 299 variables, $\mathbf{s}_{i}$.

301 More specifically, in Eq. (8), two components, $\boldsymbol{\Pi} \mathbf{s}_{i}$ and $\mathbf{L} \boldsymbol{\omega}_{i}$ are introduced to allow the 302 coefficients to vary with different levels. First, $\Pi \mathbf{s}_{i}$ is a linear function depending on the 303 intersection/corridor related variables, $\mathbf{s}_{i}$. The primary purpose of using $\boldsymbol{\Pi} \mathbf{s}_{i}$ is to capture the 
304 observed heterogeneity across different intersections and corridors. It is expected that the varying 305 intersections and corridor features (e.g., number of legs at an intersection, number of

306 through/left/right lanes at an intersection, speed limit difference between a major street and a 307 minor street at an intersection, and signalized intersection distance on a corridor) may lead to 308 different crash severity. This specification of $\boldsymbol{\Pi s}_{i}$ is the same as reported in (Huang et al., 2008).

309 Second, $\mathbf{L} \boldsymbol{\omega}_{i}$ represents random effects, which capture both the intersection/corridor-level

310 variability (Level 2) and the crash-level variability (Level 1). The primary purpose of using $\mathbf{L} \boldsymbol{\omega}_{i}$

311 is to capture the unobserved heterogeneity in the crash data. These random effects are assumed

312 not only to vary across various intersection/corridors (Level 2) but also to vary for the crashes

313 (Level 1) within the same intersection/corridor. This specification of random effects is different

314 from the (Huang et al., 2008) study, in which it is assumed that the random effects only vary

315 across different crashes (Level 2 in the model of the (Huang et al., 2008) study), whereas they

316 are kept the same for all the driver-vehicle units (Level 1 in the model of the (Huang et al., 2008)

317 study) within the same crash.

319 The conditional mean of the parameters (Sarrias, 2016), conditional on the specific data of each 320 crash is estimated by Simulated Maximum likelihood (SML) procedure, which is expressed as:

$$
\hat{E}\left(\boldsymbol{\beta}_{i} \mid \text { data }_{i}\right)=\sum_{r=1}^{R}\left(\frac{\hat{P}\left(\mathbf{y}_{i} \mid \mathbf{X}_{i}, \boldsymbol{\beta}_{i r}\right)}{\sum_{r=1}^{R} \hat{P}\left(\mathbf{y}_{i} \mid \mathbf{X}_{i}, \boldsymbol{\beta}_{i r}\right)}\right) \hat{\boldsymbol{\beta}}_{i r}
$$

322 where, $\hat{\boldsymbol{\beta}}_{i r}=\hat{\boldsymbol{\beta}}+\hat{\boldsymbol{\Pi}} \mathbf{s}_{i}+\hat{\mathbf{L}} \boldsymbol{\omega}_{i r} ; \hat{P}\left(\mathbf{y}_{\mathbf{i}} \mid \mathbf{X}_{\mathbf{i}}, \boldsymbol{\beta}_{i r}\right)$ is the estimated simulated probability for a crash $i$

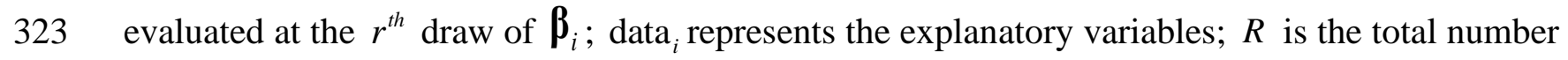


324 of draws in the SML procedure. The random draws are generated by a Halton random number 325 generator with a standard uniform distribution, $U(0,1)$. Detail Halton draws procedure can be 326 found in (Sarrias, 2016).

\section{$327 \quad 3.3 \quad$ Model implementation and estimation}

328 The random-parameter ordered regression models are estimated through the SML procedure

329 described in (Sarrias, 2016). R software is used to perform SML procedure to obtain model 330 estimation results using the "Rchoice" library (Sarrias, 2016). 300 Halton draws are used in the

331 SML procedure, which is in line with a previous study (Khattak et al., 2019a). "Rchoice" library

332 provides some options of distributions for random parameters, such as normal distribution and

333 uniform distribution. Different distributions of random parameters are implemented and tested in

334 the models. Eventually, the uniform distribution is used since it provides a better model fit. The

335 signs of the coefficient of predictors are of particular interest. In the model estimation results in

336 this paper, a positive sign of the coefficient of predictors is associated with higher crash severity

337 (i.e., $\mathrm{C}$ and $\mathrm{KAB}$ ), whereas a negative sign of the coefficient is associated with lower crash 338 severity (i.e., O).

340 To evaluate the effect of the explanatory variables on the probability of crash severity, especially 341 on the intermediate level (i.e., C), marginal effects for the three crash severity levels (i.e., O, C,

342 and $\mathrm{KAB}$ ) are computed. The marginal effect of explanatory variables indicates the change of

343 the probability of crash severity associated with a one-unit change in the continuous variables or 344 change from " 0 " to " 1 " in the indicator variables. It should also be noted that marginal effects 345 are estimated at the sample mean of the explanatory variables using the expectation of 
346 parameters when computed for random parameters. Marginal effects for the three crash severity

347 levels are computed (Greene, 2003; Washington et al., 2020) as follows:

$348 \quad \frac{\partial p\left(y_{i}=0\right)}{\partial x}=-\varphi(-\mathbf{X} \boldsymbol{\beta}) \boldsymbol{\beta}$

$349 \frac{\partial p\left(y_{i}=1\right)}{\partial x}=\varphi(-\mathbf{X} \boldsymbol{\beta}) \boldsymbol{\beta}-\varphi\left(\mu_{1}-\mathbf{X} \boldsymbol{\beta}\right) \boldsymbol{\beta}$

$350 \quad \frac{\partial p\left(y_{i}=2\right)}{\partial x}=\varphi\left(\mu_{1}-\mathbf{X} \boldsymbol{\beta}\right) \boldsymbol{\beta}$

351 where, $\varphi$ is the standard normal Probability Density Function (PDF) for the ordered probit

352 model or logistic PDF for the ordered logit model; $x$ is the explanatory variable.

354 The Variance Inflation Factor (VIF) is used to check for potential Multi-Collinearity (MC).

355 Commonly a VIF of 10 has been used by many researchers as a rule of thumb to indicate severe

356 MC issues (O'brien, 2007). The best fit models are selected based on a comparison of the Akaike

357 Information Criteria (AIC) (Burnham and Anderson, 2004), with the model with the lowest AIC

358 value deemed the best fit model. Also, the likelihood ratio test (Washington et al., 2020) is used

359 to select a model with better goodness of fit of the model. Three classification model

360 performance metrics: accuracy, precision, and recall, which are widely used for evaluating a

361 classification model, are used for evaluating the performance of the random-parameter ordered

362 regression model (i.e., ordered probit or logit) with observed heterogeneity. A training dataset

363 with $80 \%$ of the sample and a test dataset with $20 \%$ of the sample are obtained. The training

364 dataset and test dataset are randomly sampled. During the sampling, both datasets are ensured to

365 have similar percentages of data points by category (i.e., by crash severity outcomes). The

366 sampling procedure is repeated 30 times (Rahman et al., 2019; Xie et al., 2019). For each time, 
367 the model is developed using the training dataset, and then the model is evaluated using the test

368 dataset. The accuracy, precision, and recall are computed for the test dataset using Eq. (13) to

369 Eq. (15) (Sammut Claude and Webb, 2010; Ting, 2010).

$370 \quad$ Accuracy $=C T / N$

$371 \quad$ Precision $=T P_{t} /\left(T P_{t}+F P_{t}\right)$

$372 \quad$ Recall $=T P_{t} /\left(T P_{t}+F N_{t}\right)$

373 where, $C T$ is the total number of correctly classified instances for all classes; $N$ is the total

374 number of instances for all classes; $t$ is the class label (i.e., $\mathrm{O}, \mathrm{C}$, or $\mathrm{KAB}$ ); $T P_{t}$ is true positive

375 for the class label $t ; F P_{t}$ is false positive for the class label $t ; F N_{t}$ is false negative for the class

376 label $t$.

377

378 Overall precision and recall are evaluated by computing the micro-average values of precision 379 and recall (Van Asch, 2013), which are derived by Eq. (16) and Eq. (17).

$380 \quad$ Precision $_{\text {Micro-average }}=\sum_{t=1}^{T} T P_{t} /\left(\sum_{t=1}^{T} T P_{t}+\sum_{t=1}^{T} F P_{t}\right)$

$381 \quad$ Recall $_{\text {Micro-average }}=\sum_{t=1}^{T} T P_{t} /\left(\sum_{t=1}^{T} T P_{t}+\sum_{t=1}^{T} F N_{t}\right)$

383 where, $T$ is the total number of classes, including three classes (i.e., O, C, and KAB) in this 384 paper.

385

\section{Data description}

387 Initially, the authors obtained crash data from 13 corridors that have installed ASCS. Original

388 crash data have before period and after period data. The authors only include corridors that have 
389 at least a two-year after period crash data for this study. As listed in Table 1, there is a total of

390 six corridors (one in Lexington, one in Greenville, two in Charleston, one in Pawleys Island, and

391 one in Summerville) with a total of 65 intersections where ASCS has been deployed. In total,

3926,570 crashes are analyzed in this study. Only one type of ASCS is investigated in this study. For

393 this specific type of ASCS, there are three main components, including server, local traffic

394 controller, and vehicle detection. The server is responsible for processing data and calculating

395 updated signal timings. The local traffic controller is responsible for gathering detection data and

396 executing the commands received from the server. The interaction between the server and the

397 local traffic controller is performed every few seconds to ensure signal timings are always up-to-

398 date. The primary objective of the algorithm of this type of ASCS is to minimize traffic delays at

399 the intersections while ensuring reasonable progression bandwidth of the corridor. This type of 400 ASCS optimizes the cycle length, splits, and offsets based on real-time traffic conditions. By 401 handling conflicting traffic movements and establishing dynamic coordination between 402 intersections in real-time, ASCS can smooth traffic flow and reduce traffic congestion, thus 403 potentially yielding safety benefits for signalized intersections.

404

405 Table 1 Corridor Information

\begin{tabular}{lllll}
\hline Location & Corridor & $\begin{array}{l}\text { Number } \\
\text { of }\end{array}$ & Installation Date & $\begin{array}{l}\text { Number of } \\
\text { Crashes at }\end{array}$ \\
& Name & Signals & & Intersections \\
\hline Greenville & Roper Mt Rd/ & 5 & November 2016 & 193 \\
& Garlington Rd & & & \\
Charleston & SC 642 & 18 & June 2015 & 931
\end{tabular}




\begin{tabular}{lllll}
\hline Location & Corridor & $\begin{array}{l}\text { Number } \\
\text { of }\end{array}$ & Installation Date & $\begin{array}{l}\text { Number of } \\
\text { Crashes at }\end{array}$ \\
& Name & Signals & & Intersections \\
& & 17 & October 2016 & 2387 \\
\hline Charleston & US 52 & 7 & December 2015 & 502 \\
Lexington & N Lake Drive & 7 & February 2016 & 552 \\
Pawleys & US 17 & 6 & & \\
Island & & & June 2015 & 2005 \\
Summerville & US 17A & 12 & & \\
\hline
\end{tabular}

407 According to SCDOT, the intersection-related crashes are those that occurred within 0.05 miles 408 of the center of the intersection. Using the threshold of 0.05 miles, the intersection-related 409 crashes are identified. Crash data are collected for all study corridors from 2011 to 2018. Crash 410 data of six months after the installation of ASCS are removed from the analysis, which 411 eliminates the effect of acclimation to ASCS of drivers. As shown in Table 2, around $79 \%$ of 412 the crashes are $\mathrm{O}$ (i.e., no injury), and a small proportion (around $6 \%$ ) of the crash is KAB (i.e., 413 fatal, incapacitating injury, and non-incapacitating injury combined).

414

415 Table 2 Frequency (and percentage) of Crash Severity

Crash Severity $\quad$ Frequency (Percentage)

\section{Outcome}

\begin{tabular}{ll}
\hline $\mathrm{O}^{*}$ & $5182(78.9 \%)$ \\
$\mathrm{C}^{*}$ & $1005(15.3 \%)$ \\
$\mathrm{KAB}^{*}$ & $383(5.8 \%)$ \\
\hline
\end{tabular}


*KABCO crash severity scale. KAB: fatal, incapacitating injury, and non-incapacitating injury combined, C:

417 possible injury, and O: no injury

In order to properly analyze the crash data, the authors collect information from SCDOT 420 regarding whether any other possible safety improvements, in addition to the ASCS, have been

421 implemented at intersections. Flashing Yellow Arrow (FYA) was installed on some signalized 422 intersections before or after the ASCS was installed. Although only $3.9 \%$ (256 out of 6,570) of 423 the observations have FYA, FYA may affect the crash severity outcome. Therefore, the authors 424 initially consider FYA as one of the explanatory variables of the model. A categorical variable is 425 considered to distinguish the effects of different numbers of FYA at the intersections on the 426 crash severity outcomes. It is found that the categorical variable is not significant and adding the 427 categorical variable increases AIC of the model. Thus, the FYA variable is taken out of the 428 model since it cannot provide useful information. Left-turn lanes were modified at one 429 intersection in one of study corridors after the ASCS was installed. To exclude the effect of such 430 improvements that may impact safety, the crashes that occurred at this intersection are not 431 included in the analysis. An additional signal phase was added to one signal after the ASCS was 432 installed; thus, the crashes located at this intersection are not included in the analysis as well.

434 Table 3 shows a summary of descriptive statistics of the geometric features of intersections and 435 speed limit data. The difference in the geometric features of intersections and speed limit 436 between before period and after period is very small.

438 Table 3 Descriptive Statistics of Geometric Features of Intersections and Speed Limit Data

\begin{tabular}{lllllllll}
\hline \multirow{2}{*}{ Variables } & \multicolumn{3}{c}{ Before Period } & \multicolumn{3}{c}{ After Period } \\
\cline { 2 - 7 } & Mean & S.D. ${ }^{\text {a }}$ & Min & Max & Mean & S.D. ${ }^{\text {a }}$ & Min & Max \\
\hline
\end{tabular}




\begin{tabular}{|c|c|c|c|c|c|c|c|c|}
\hline \multirow{2}{*}{ Variables } & \multicolumn{4}{|c|}{ Before Period } & \multicolumn{4}{|c|}{ After Period } \\
\hline & Mean & S.D. ${ }^{a}$ & Min & Max & Mean & S.D. ${ }^{a}$ & Min & Max \\
\hline Number of legs at intersections & 3.82 & 0.38 & 3 & 4 & 3.80 & 0.40 & 3 & 4 \\
\hline Number of through lane(s) on major roads & 5.37 & 1.44 & 2 & 8 & 5.29 & 1.28 & 2 & 8 \\
\hline $\begin{array}{c}\text { Number of the exclusive right-turn lane(s) on } \mathrm{m} \\
\text { roads }\end{array}$ & 1.20 & 0.80 & 0 & 2 & 1.16 & 0.84 & 0 & 2 \\
\hline $\begin{array}{l}\text { Number of the exclusive left-turn lane(s) on ma } \\
\text { roads }\end{array}$ & 2.28 & 0.91 & 0 & 4 & 2.22 & 0.89 & 0 & 4 \\
\hline Number of through lane(s) on minor roads & 2.16 & 1.21 & 0 & 5 & 2.14 & 1.19 & 0 & 5 \\
\hline $\begin{array}{l}\text { Number of the exclusive right-turn lane(s) on } \mathrm{m} \\
\text { roads }\end{array}$ & 1.02 & 0.70 & 0 & 2 & 0.87 & 0.75 & 0 & 2 \\
\hline $\begin{array}{l}\text { Number of the exclusive left-turn lane(s) on mi } \\
\text { roads }\end{array}$ & 1.81 & 0.89 & 0 & 4 & 1.89 & 0.89 & 0 & 4 \\
\hline Number of access points on major roads & 3.03 & 1.75 & 0 & 7 & 3.27 & 1.80 & 0 & 7 \\
\hline Number of access points on minor roads & 2.38 & 1.92 & 0 & 7 & 2.39 & 1.88 & 0 & 7 \\
\hline Speed limit on major roads (mph) & 42.64 & 5.00 & 25 & 55 & 41.47 & 5.53 & 25 & 55 \\
\hline Speed limit on minor roads (mph) & 32.15 & 4.89 & 25 & 50 & 31.78 & 4.71 & 25 & 50 \\
\hline
\end{tabular}

${ }^{a}$ S.D.-Standard deviation

441 The following crash attributes are provided by SCDOT: collision time, crash severity, Annual

442 Average Daily Traffic (AADT), light condition, road surface condition, crash type, weather

443 condition, work zone, first harmful event, and probable cause. The purpose of the inclusion of

444 the first harmful event is to determine the involvement of pedestrians. The purpose of the

445 inclusion of probable cause is to identify the careless (distracted) or aggressive drivers (i.e., 446 aggressive operation of the vehicle or at excessive speed). The light (dawn, daylight, dusk or 447 dark), and weather conditions (rain or not) are accounted for because those attributes may impact 
448 crash severity. Peak periods for each corridor analyzed in this study are identified by analyzing

449 hourly average travel time data provided by the Iteris ClearGuide system (Iteris, 2020). The peak

450 periods only exist on weekdays for the study corridors, and we found that the hourly average

451 travel time does not vary much over the $24 \mathrm{~h}$ during weekends on our study corridors. That is

452 why only weekday peak periods are considered in this paper, as shown in Table 4. Crash data

453 available for South Carolina and provided by the SCDOT do not map crashes to traffic signal

454 status (green, yellow, or red) (SCDOT, 2020a). Consequently, each crash cannot be associated

455 with a specific signal phase from the available data. Due to this limitation, signal related

456 parameters, such as signal status (green, yellow or red) and green/yellow/red time, could not be

457 introduced into the model.

458

459 Table 4 Peak Periods for the Study Corridors

\begin{tabular}{lll}
\hline Location & Corridor Name & Peak Period \\
\hline Greenville & Roper Mt Rd/ Garlington Rd & $7: 00-10: 00$ \\
& & $16: 00-19: 00$ \\
Charleston & SC 642 & $6: 00-9: 00$ \\
& & $15: 30-18: 30$ \\
Charleston & US 52 & $7: 00-10: 00$ \\
& & $14: 00-18: 00$ \\
Lexington & N Lake Drive & $7: 00-10: 00$ \\
& & $15: 00-19: 00$ \\
Pawleys Island & US 17 & $11: 00-15: 00$ \\
Summerville & US 17A & $11: 00-14: 00$ \\
\hline
\end{tabular}




\begin{tabular}{lll}
\hline Location & Corridor Name & Peak Period \\
\hline & & $16: 00-19: 00$
\end{tabular}

461 The attributes from the crash database are converted to the response and explanatory variables.

462 The response variable includes three crash severity levels- $\mathrm{O}, \mathrm{C}$, and $\mathrm{KAB}$. The explanatory 463 variables include light condition, ASCS presence, FYA presence, peak period, crash type (rear464 end or angle), weather condition, careless driving, aggressive driving, the presence of 465 pedestrians, and AADT. Also, the authors have collected area type (urban or not) and speed limit 466 data from the SCDOT website (SCDOT, 2020b), and corridor geometric features (i.e., the 467 average distance between signalized intersections) from Google Earth. The descriptive statistics 468 for the response and the significant explanatory variables for both before period and after period 469 are shown in Table 5. A Pearson correlation test between AADT and the peak period is 470 conducted, and it is found that there is no correlation between AADT and the peak period in our 471 study. A high traffic volume may be associated with a higher crash severity. An AADT threshold 472 of 30,000 is used to identify relatively high traffic volume in this study based on a previous study 473 (Fink et al., 2016). A threshold of $10 \mathrm{mph}$ speed difference between a major road and a minor 474 road at an intersection is used to divide the observations into two groups (one group for which 475 the speed limit difference between a major road and a minor road is equal to or greater than 10 $476 \mathrm{mph}$; another group for which the speed limit difference between a major road and a minor road 477 is less than $10 \mathrm{mph}$ ) because, based on our analysis, the median speed limit difference between a 478 major road and a minor road in the sample is about $10 \mathrm{mph}$. In this study, all explanatory 479 variables are tested in terms of MC. It is found that the maximum value of VIF is 2.37 . Thus, the 480 MC issue should not be of concern for the variables considered in this study. The authors 481 initially include the interaction variables into the model to account for the interaction between 
482 ASCS and angle crash and the interaction between ASCS and rear-end crash in the model.

483 However, the interaction variables are not significant and adding these interaction variables

484 increases the AIC of the model. Therefore, the interaction variables are later excluded from the

485 model.

486

487 Table 5 Summary of Descriptive Statistics of Response Variables and Significant

488 Explanatory Variables

\begin{tabular}{|c|c|c|c|c|}
\hline Variable & Definition & $\begin{array}{c}\text { Level/Data } \\
\text { Type }\end{array}$ & $\begin{array}{l}\text { Before Period } \\
\text { Frequency } \\
\text { (Percentage) }\end{array}$ & $\begin{array}{l}\text { After Period } \\
\text { Frequency } \\
\text { (Percentage) }\end{array}$ \\
\hline \multirow{3}{*}{ Crash_Severity } & \multirow{3}{*}{ Crash severity outcome } & $0-\mathrm{O}$ & $3093(77.7 \%)$ & $2089(80.6 \%)$ \\
\hline & & $1-\mathrm{C}$ & $631(15.9 \%)$ & $374(14.4 \%)$ \\
\hline & & $2-\mathrm{KAB}$ & $255(6.4 \%)$ & $128(4.9 \%)$ \\
\hline \multirow{2}{*}{ Light } & \multirow{2}{*}{ Dark ( 1 if dark, otherwise 0 ) } & 1 & $912(22.9 \%)$ & $579(22.3 \%)$ \\
\hline & & 0 & $3067(77.1 \%)$ & $2012(77.7 \%)$ \\
\hline \multirow{2}{*}{$A S C S$} & The presence of ASCS ( 1 if Yes, & 1 & - & $2591(39.4 \%)$ \\
\hline & otherwise 0 ) & 0 & $3979(60.6 \%)$ & - \\
\hline \multirow{2}{*}{ Peak } & \multirow{2}{*}{ Peak period ( 1 if peak period, otherwise 0 ) } & 1 & $1075(27.0 \%)$ & $698(26.9 \%)$ \\
\hline & & 0 & $2904(73.0 \%)$ & $1893(73.1 \%)$ \\
\hline \multirow[b]{2}{*}{ Rear_end } & \multirow[b]{2}{*}{ Rear-end ( 1 if rear-end, otherwise 0 ) } & 1 & $2140(53.8 \%)$ & $1335(51.5 \%)$ \\
\hline & & 0 & $1839(46.2 \%)$ & $1256(48.5 \%)$ \\
\hline \multirow{2}{*}{ Angle } & \multirow{2}{*}{ Angle ( 1 if angle, otherwise 0 ) } & 1 & $1073(27 \%)$ & $672(25.9 \%)$ \\
\hline & & 0 & $2906(73 \%)$ & $1919(74.1 \%)$ \\
\hline \multirow{2}{*}{ Pedestrian } & The presence of pedestrian ( 1 if & 1 & $21(0.5 \%)$ & $12(0.5 \%)$ \\
\hline & pedestrian-involved, otherwise 0 ) & 0 & 3958 (99.5 \%) & $2579(99.5 \%)$ \\
\hline
\end{tabular}




\begin{tabular}{|c|c|c|c|c|}
\hline Variable & Definition & $\begin{array}{c}\text { Level/Data } \\
\text { Type }\end{array}$ & $\begin{array}{l}\text { Before Period } \\
\text { Frequency } \\
\text { (Percentage) }\end{array}$ & $\begin{array}{l}\text { After Period } \\
\text { Frequency } \\
\text { (Percentage) }\end{array}$ \\
\hline & AADT at a road on which a crash & 1 & $3256(81.8 \%)$ & $2272(87.7 \%)$ \\
\hline$A A D T \_o v e r \_30 k$ & $\begin{array}{l}\text { occurred ( } 1 \text { if greater than } 30 \mathrm{k} \text {, otherwise } \\
0)\end{array}$ & 0 & $723(18.2 \%)$ & $319(12.3 \%)$ \\
\hline \multirow{3}{*}{ S_Difover10 } & Speed limit difference between major & 1 & $2894(72.7 \%)$ & $1882(70.3 \%)$ \\
\hline & $\begin{array}{l}\text { roads and minor roads at an intersection (1 } \\
\text { if equal to or greater than } 10 \mathrm{mph} \text {, } \\
\text { otherwise } 0)\end{array}$ & 0 & $1085(27.3 \%)$ & $769(29.7 \%)$ \\
\hline & & & $\operatorname{Mean}\left(S . D^{a}\right)$ & $\operatorname{Mean}\left(S . D^{a}\right)$ \\
\hline Speed_Limit & Speed limit (mph) & Numeric & $40.71(6.20)$ & $39.83(6.33)$ \\
\hline Signal Distance & $\begin{array}{l}\text { Average signal distance on a corridor } \\
\text { (miles) }\end{array}$ & Numeric & $0.38(0.12)$ & $0.36(0.12)$ \\
\hline
\end{tabular}

${ }^{\mathrm{a}}$ S.D.-Standard deviation

\section{$490 \quad 5 \quad$ Results and analysis}

491 Four random-parameter ordered regression models are firstly compared. The model estimation

492 results on the association between the presence of ASCS and the crash severity and the

493 relationship between other contributing factors and the crash severity are then presented.

\section{$494 \quad 5.1$ Comparison of random-parameter ordered regression models}

495 The following four models are estimated and compared:

496 - Random-parameter ordered probit model with observed heterogeneity (ROP)

497 - Random-parameter ordered logit model with observed heterogeneity (ROL) 
- Random-parameter ordered probit model (RP)

- Random-parameter ordered logit model (RL)

501 In the model estimation results in Table 6, a positive sign of the coefficient of predictors is 502 associated with higher crash severity, while a negative sign of the coefficient is associated with 503 lower crash severity. From the negative sign of the coefficient (i.e., -0.113 for the RP model and $504-0.205$ for the RL model) of the ASCS variable in Table 6, it shows that the presence of ASCS is 505 associated with lower crash severity. Since the standard deviation associated with ASCS is found 506 to be statistically insignificant in the RP, RL, ROP, and ROL models, ASCS is not considered as 507 a random parameter for these models. Instead, ASCS is considered as a fixed parameter for the 508 RP and RL models, and a varying parameter depending on intersection/corridor-level variables 509 (i.e., S_Difover10 and Signal Distance) for the ROP and ROL models. Only the angle variable is 510 considered as a random parameter with the mean (i.e., mean.Angle) and the standard deviation 511 (i.e., S.D. Angle) in these models.

\section{Table 6 Model Estimation Results}

\begin{tabular}{ccccccccc}
\hline & \multicolumn{2}{c}{ ROP $^{\mathrm{a}}$} & \multicolumn{2}{c}{ ROL $^{\mathrm{a}}$} & \multicolumn{2}{c}{ RP $^{\mathbf{a}}$} & \multicolumn{2}{c}{ RL $^{\mathbf{a}}$} \\
\hline Coefficients & Est. & p-value & Est. & p-value & Est. & p-value & Est. & p-value \\
\hline Threshold, $\mu_{1}{ }^{\mathrm{b}}$ & 0.858 & $<0.001$ & 1.675 & $<0.001$ & 0.855 & $<0.001$ & 1.671 & $<0.001$ \\
Constant & -1.554 & $<0.001$ & -2.822 & $<0.001$ & -1.618 & $<0.001$ & -2.947 & $<0.001$ \\
Pedestrian & 2.078 & $<0.001$ & 3.711 & $<0.001$ & 2.061 & $<0.001$ & 3.660 & $<0.001$ \\
AADT_over_30k & 0.235 & $<0.001$ & 0.425 & $<0.001$ & 0.225 & $<0.001$ & 0.405 & $<0.001$ \\
Speed_Limit & 0.009 & 0.008 & 0.019 & $<0.001$ & 0.011 & 0.001 & 0.022 & $<0.001$ \\
Light & 0.324 & $<0.001$ & 0.553 & $<0.001$ & 0.321 & $<0.001$ & 0.543 & $<0.001$
\end{tabular}




\begin{tabular}{|c|c|c|c|c|c|c|c|c|}
\hline Rear_end & 0.133 & 0.006 & 0.319 & $<0.001$ & 0.134 & 0.005 & 0.318 & $<0.001$ \\
\hline Peak & -0.090 & 0.037 & -0.178 & 0.027 & -0.093 & 0.031 & -0.183 & 0.023 \\
\hline ASCS & - & - & - & - & -0.113 & 0.002 & -0.205 & 0.003 \\
\hline mean.ASCS ${ }^{c}$ & -0.443 & $<0.001$ & -0.799 & $<0.001$ & - & - & - & - \\
\hline mean.Angle ${ }^{c}$ & 0.330 & $<0.001$ & 0.416 & 0.016 & 0.331 & $<0.001$ & 0.501 & $<0.001$ \\
\hline S_Difover10 & 0.127 & 0.071 & 0.256 & 0.055 & - & - & - & - \\
\hline Signal Distance ${ }^{\mathrm{d}}$ & 0.637 & 0.007 & 1.081 & 0.013 & - & - & - & - \\
\hline S.D.Angle ${ }^{\mathrm{e}}$ & 1.030 & $<0.001$ & 2.532 & $<0.001$ & 1.018 & $<0.001$ & 1.369 & $<0.001$ \\
\hline Log-Likelihood & -4024 & & -4025 & & -4030 & & -4031 & \\
\hline Number of observations & 6570 & & 6570 & & 6570 & & 6570 & \\
\hline AIC & 8076.28 & & 8078.20 & & 8082.41 & & 8084.15 & \\
\hline
\end{tabular}

a: ROP stands for random-parameter ordered probit model with observed heterogeneity; ROL stands for randomparameter ordered logit model with observed heterogeneity; RP stands for random-parameter ordered probit model; RL stands for random-parameter ordered logit model.

517 b: estimated threshold in Eq. (5) - (6)

518 c: mean of the coefficient

519 d: observed variable used to capture the observed heterogeneity of ASCS

520 e: standard deviation of the coefficient

522 As indicated in the previous studies, the AIC difference between two competing models that is 523 greater than 2 (Burnham and Anderson, 2004) or 2.5 (Hilbe, 2011) could be used as a threshold

524 to distinguish different models. Based on the recommendation of these studies, the difference of 525 AIC between two models greater than 2.5 is considered as the threshold to select the preferred 526 models in this study. As indicated in Table 7, the ROP and ROL models are better than the RP

527 and RL models in terms of AIC. As indicated in Table 7 (in the last two columns), in terms of 528 AIC, there are no significant differences between the ROP and ROL models, as well as between 529 the RP and RL models.

530 Table 7 Model Comparison based on AIC Difference

Model Comparisons 


\begin{tabular}{lllllll}
\hline & RL VS. & RP VS. & RL VS. & RP VS. & ROP VS. & RP VS. \\
& ROL $^{\mathbf{a}}$ & ROP & ROP & ROL $^{\mathbf{a}}$ & ROL $^{\mathbf{a}}$ & RL $^{\mathbf{a}}$ \\
\hline AIC difference & 5.95 & 6.13 & 7.87 & 4.21 & 1.92 & 1.74 \\
Preferred model (with & ROL & ROP & ROP & ROL & No & No \\
a lower AIC) & & & & significant & significant \\
& & & & difference & difference
\end{tabular}

a: ROP stands for random-parameter ordered probit model with observed heterogeneity; ROL stands for randomparameter ordered logit model with observed heterogeneity; RP stands for random-parameter ordered probit model; RL stands for random-parameter ordered logit model.

In addition to using AIC, a likelihood ratio test (Washington et al., 2020) for comparing nested models (e.g., RL VS. ROL, RP VS. ROP, RL VS. ROP, RP VS. ROL) is conducted in this study to identify a superior model with better goodness of fit of the model, as shown in Table $\mathbf{8}$. The likelihood ratio Chi-squared statistics are statistically significant at a 0.05 significance level, 539 suggesting that the ROP and ROL models are better than the RP and RL models in terms of the 540 goodness of fit of the model. The likelihood ratio tests are not conducted for comparing non-

541 nested models (e.g., ROP VS. ROL, RP VS. RL) as the likelihood ratio test does not apply to 542 compare non-nested models. Based on both AIC (Table 7) and the likelihood ratio test (Table 8)

543 findings, the ROP and ROL models are better than the RP and RL models in terms of both the 544 AIC and goodness of fit of the model.

Model comparison

\begin{tabular}{|c|c|c|c|c|}
\hline & $\begin{array}{c}\text { RL VS. } \\
\text { ROL }^{\mathbf{a}}\end{array}$ & RP VS. ROPa & RL VS. ROPa & RP VS. ROL ${ }^{\mathrm{a}}$ \\
\hline Difference of degrees of & 3 & 3 & 3 & 3 \\
\hline
\end{tabular}


Model comparison

\section{RL VS.}

ROL $^{\mathrm{a}}$

\section{RP VS. ROP ${ }^{a}$ RL VS. ROPa RP VS. ROL ${ }^{a}$}

competing models

Likelihood ratio Chi-squared

$\begin{array}{lcccc}\text { statistic } & 12.28 & 12.44 & 14.78 & 9.94 \\ \text { p-value } & & & & \\ & 0.006^{\mathrm{b}} & 0.006^{\mathrm{b}} & 0.002^{\mathrm{b}} & 0.02^{\mathrm{b}}\end{array}$

Superior model (with better

goodness of fit of the model)

ROL ROP ROP ROL

a: ROP stands for random-parameter ordered probit model with observed heterogeneity; ROL stands for randomparameter ordered logit model with observed heterogeneity; RP stands for random-parameter ordered probit model; RL stands for random-parameter ordered logit model.

b statistically significant at a 0.05 significance level.

560 For each time, the model is developed using the training dataset, and then the model is evaluated

561 using the test dataset. The three metrics are evaluated for 30 times, and the results are averaged

562 and presented in Table 9. The precision and recall are evaluated for each crash severity level

563 (i.e., O, C, or KAB). Also, the overall precision and recall are evaluated by computing the micro-

564 average values of the precision and recall, and the results are shown in Table 9. A $t$-test is 
565 conducted to determine if the means of evaluated metrics for the ROP and ROL models

566 are significantly different from each other. In terms of accuracy, overall precision, and overall

567 recall, the ROP model outperforms the ROL model. The results of accuracy, overall precision,

568 and overall recall for the ROP and ROL models are significantly different from each other at a

5690.05 significance level.

570

Table 9 Classification Model Performance Metrics

\begin{tabular}{llllllllll}
\hline Model & Accuracy & Precision & & & & Recall & \\
\hline & Overall & For O & For C & $\begin{array}{l}\text { For } \\
\text { KAB }\end{array}$ & $\begin{array}{l}\text { Overall } \\
\text { (Micro- } \\
\text { average) }\end{array}$ & For O & For C & $\begin{array}{l}\text { For } \\
\text { KAB }\end{array}$ & $\begin{array}{l}\text { Overall } \\
\text { (Micro- } \\
\text { average) }\end{array}$ \\
\hline ROP $^{\#}$ & $74.8 \%^{\mathrm{a}}$ & $80.0 \%$ & $19.1 \%^{\mathrm{b}}$ & $49.5 \%^{\mathrm{a}}$ & $74.8 \%^{\mathrm{a}}$ & $92.5 \%^{\mathrm{a}}$ & $10.5 \%^{\mathrm{a}}$ & $3.9 \%$ & $74.8 \%^{\mathrm{a}}$ \\
ROL $^{\#}$ & $72.6 \%^{\mathrm{a}}$ & $80.1 \%$ & $17.8 \%^{\mathrm{b}}$ & $37.5 \%^{\mathrm{a}}$ & $72.6 \%^{\mathrm{a}}$ & $89.1 \%^{\mathrm{a}}$ & $13.5 \%^{\mathrm{a}}$ & $4.3 \%$ & $72.6 \%^{\mathrm{a}}$ \\
\hline
\end{tabular}

\#: ROP stands for random-parameter ordered probit model with observed heterogeneity; ROL stands for random-

573 parameter ordered logit model with observed heterogeneity

574 a: results of ROP and ROL are statistically different at a 0.05 significance level

575 b: results of ROP and ROL are statistically different at a 0.1 significance level

\subsection{ASCS effects on crash severity}

578 Since the ROP model is deemed as best based on the discussion in Subsection 5.1, only ROP

579 model estimation results are discussed here. As shown in Table 6, observed heterogeneity of

580 ASCS is estimated by two intersection/corridor-level variables (i.e., S_Difover10 and Signal

581 Distance). Other variables related to intersection features such as the number of legs at an

582 intersection and the number of through/left/right lanes at an intersection are attempted in the

583 model, but these variables are not significant. Other variables related to corridor features such as

584 average AADT on a corridor are tried in the model, but they are not significant. 
586 The coefficient of the ASCS variable is a function of intersection/corridor-level variables (i.e.,

587 speed limit difference between a major road and a minor road at an intersection that is equal to or

588 greater than $10 \mathrm{mph}$ or S_Difover10, and average signal distance on a corridor or Signal

589 Distance). Based on the estimation of the coefficient, the coefficient of the ASCS variable in the

590 ROP model can be expressed as,

$591 \beta_{\text {ASCS }, i}=-0.443+0.127\left(x_{S_{-} \text {Difover } 10, i}\right)+0.637\left(x_{\text {Signal Distance, } i}\right)$

592 where, $i$ is an observation ID (i.e., a specific crash). $x_{S_{-} \text {Diffover } 10, i}$ is 1 if the speed limit difference

593 between a major street and a minor street at an intersection is equal to or greater than $10 \mathrm{mph}$ and

594 otherwise is $0 . x_{\text {Signal Distance, } i}$ is the average signal distance on a corridor.

595

596 Figures 2 to 4 show observed heterogeneity in terms of coefficient of the ASCS variable

597 estimated by the ROP model, which represents hierarchical effects of ASCS on the crash

598 severity. The hierarchical effects of ASCS on the crash severity represent the ASCS effect varied

599 by intersection and corridor features. Based on Eq. (18), two linear functions are plotted in

600 Figure 2. In Figure 2, a negative coefficient in the y-axis indicates that the presence of ASCS is

601 associated with lower crash severity, whereas a positive coefficient indicates that the presence of

602 ASCS is associated with higher crash severity. The following observations are derived from

603 Figure 2:

604 - In Case 1, where speed limit difference between a major street and a minor street at an 605 intersection (intersection feature) is equal to or greater than $10 \mathrm{mph}$, the coefficient of 606 ASCS increases as the average signal distance on a corridor increases. When the average 607 signal distance on a corridor (corridor feature) exceeds the threshold of 0.49 miles for 
Case 1, the coefficient of ASCS becomes positive, suggesting that the presence of ASCS is associated with higher crash severity.

- In Case 2, where speed limit difference between a major street and a minor street at an intersection is less than $10 \mathrm{mph}$, the coefficient of ASCS increases as the average signal distance on a corridor increases. When the average signal distance on a corridor exceeds the threshold of 0.69 miles for Case 2, the coefficient of ASCS becomes positive, suggesting that the presence of ASCS is associated with higher crash severity. a minor street at an intersection (i.e., less than $10 \mathrm{mph}$ ) is less likely to increase the crash severity, the larger signal distance on a corridor can be accepted to deploy the ASCS without increasing the probability of higher crash severity.

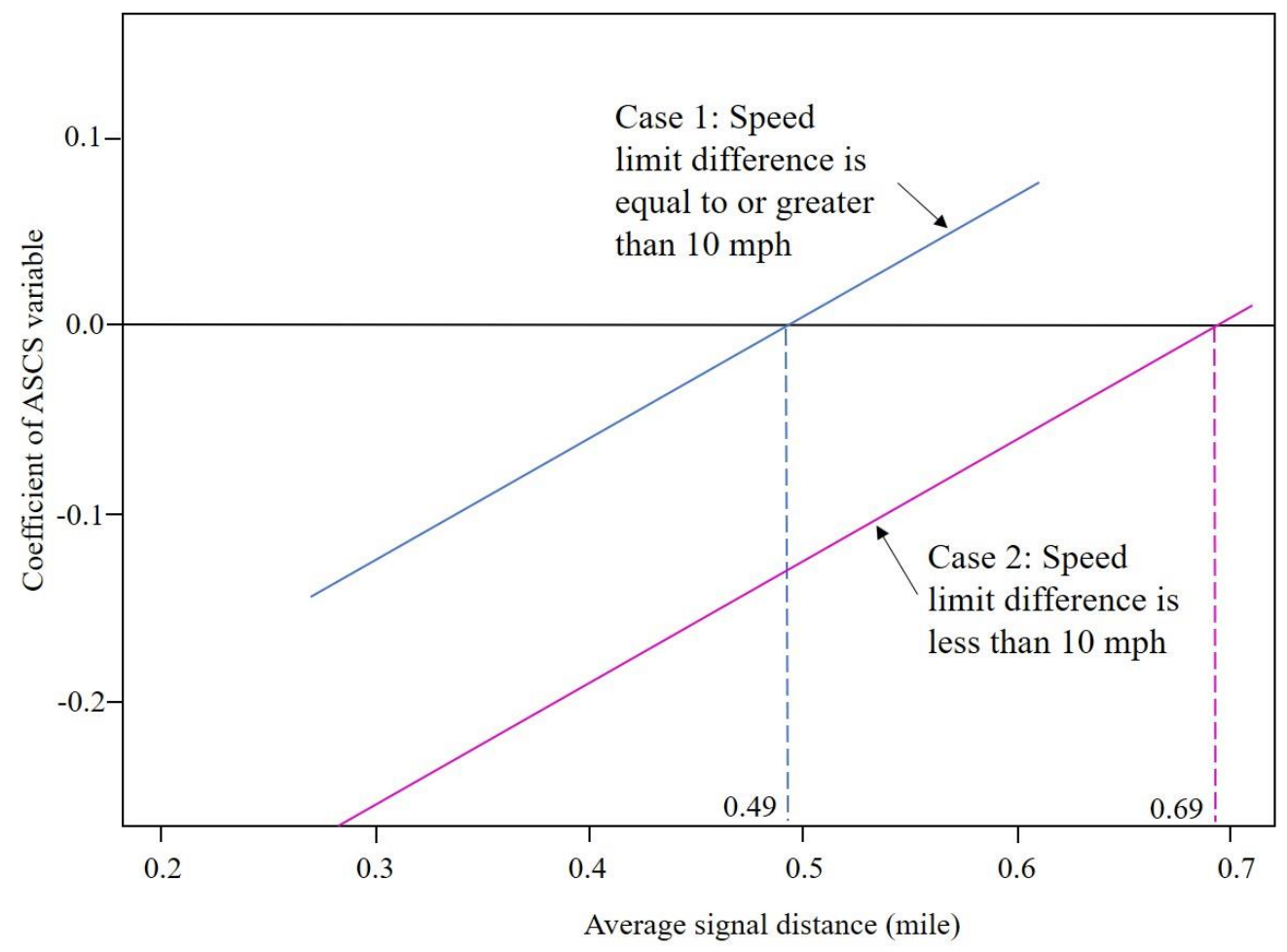


623 Figure 3 shows the kernel density of conditional means of the coefficient of the ASCS variable.

624 The conditional means of the coefficient of the ASCS variable is calculated by using Eq. (9). It

625 turns out that the majority (78\%) of the conditional means (the unshaded portion in the figure)

626 has negative signs, suggesting that the presence of ASCS is associated with lower crash severity

627 for most of the observations. It is concluded that the presence of ASCS is associated with lower 628 crash severity.

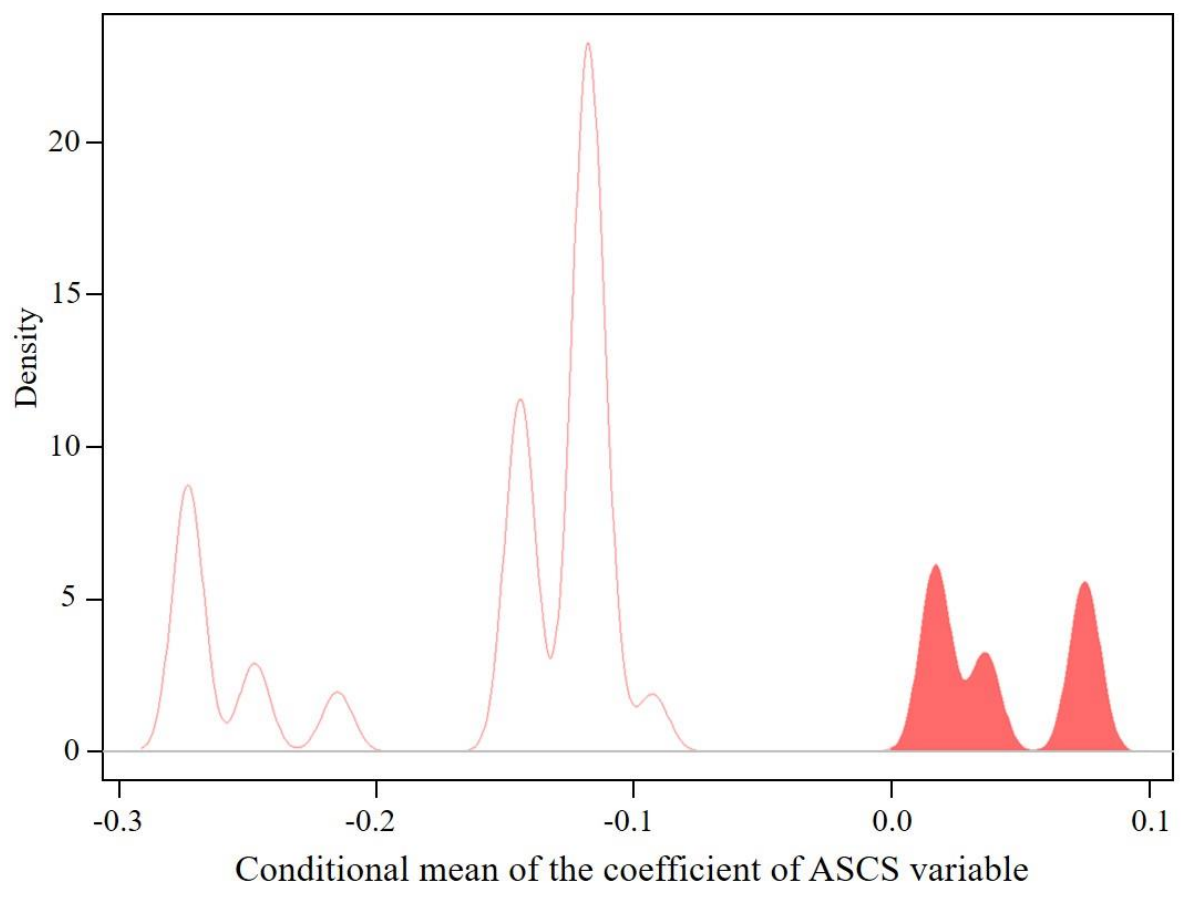

632 Figure 4 shows $95 \%$ confidence intervals for the conditional means of the coefficient of the 633 ASCS variable in the ROP model for observation IDs from 2600 to 2800 (total number of 634 observations in the sample is 6,570 in this study). The ASCS effect on crash severity varies 635 across different intersections and corridors. In contrast, some crashes have the same ASCS effect 
636 since they occurred at a similar intersection (same speed limit difference category) on the same 637 corridor.

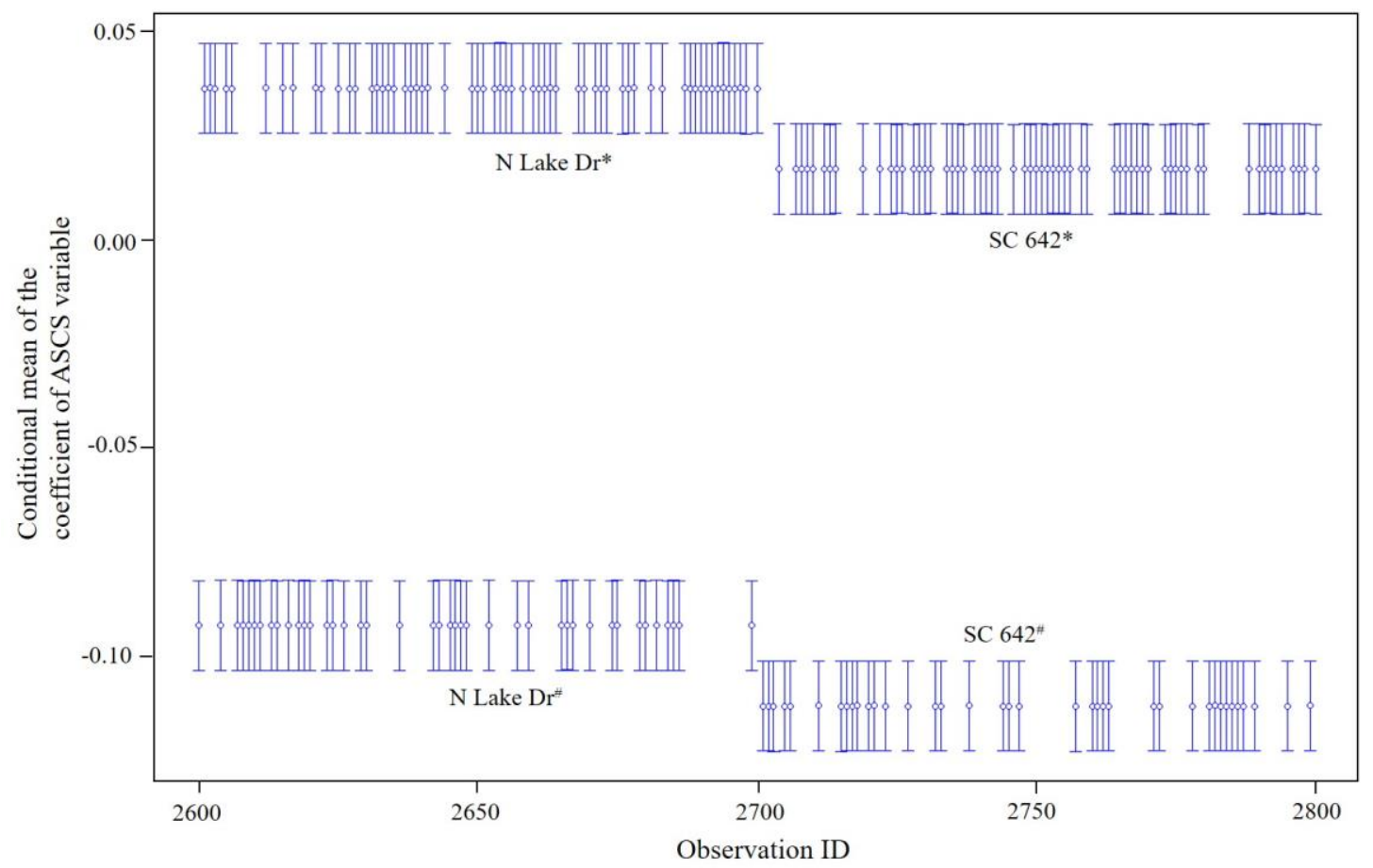

640 Figure 4: $95 \%$ confidence intervals for the conditional means of the coefficient of the ASCS variable in the ROP model for observation IDs from 2600 to 2800

$642 *$ : Crashes that occurred at intersections where speed limit difference between major streets and minor streets is 643 equal to or greater than $10 \mathrm{mph}$

644 \#: Crashes that occurred at intersections where speed limit difference between major streets and minor streets is less 645 than $10 \mathrm{mph}$

647 The marginal effects for the three crash severity levels are computed, as shown in Table 10. A 648 positive sign of the value in the marginal effects table indicates an increase in the probability of a 649 severity level for the ASCS variable, meaning that such a level is indeed likely to increase due to 650 ASCS. However, a negative sign of the value in the marginal effects table indicates a decrease in 
651 the probability of the severity level for the ASCS variable, meaning that such a level is likely to 652 decrease due to ASCS.

654 The marginal effects in Table $\mathbf{1 0}$ show that ASCS can reduce the probability of C and KAB for 655 the majority of intersections and corridors except for the N Lake Dr, SC 642, and US 17 with 656 speed limit difference between major roads and minor roads equal to or greater than $10 \mathrm{mph}$. The 657 marginal effects of ASCS vary in terms of intersection and corridor features. For example, for 658 US 17A with speed limit difference between major roads and minor roads less than $10 \mathrm{mph}$, 659 ASCS reduces the probability of $\mathrm{C}$ and $\mathrm{KAB}$ by $4.76 \%$ and $2.13 \%$, respectively, while 660 increasing the probability of O by $6.89 \%$. Although the absolute value of the ASCS effect on the

$661 \mathrm{KAB}$ seems to be small, for the case of the small proportion of KAB (average is around $6 \%$ ) in 662 the studied intersections, ASCS is quite effective in reducing the probability of KAB for crashes 663 that occurred at intersections. The effectiveness of reducing $\mathrm{KAB}$ (marginal effect for $\mathrm{KAB}$ 664 divided by the proportion of $\mathrm{KAB}$ for the corresponding intersections) is computed in the last 665 column in Table 10. For example, the highest benefit is achieved for Garlinton Rd by 1.76 $666 \% / 1.55 \%=113.23 \%$.

667

668 Table 10 Marginal Effects of ASCS on Crash Severity Levels

\begin{tabular}{cccccccc}
\hline Corrid & Intersection & Corridor & Marginal & Marginal & Marginal & Proportion & Effectivene \\
or & Feature & Feature & Effect for & Effect for & Effect for & of KAB & ss of
\end{tabular}




\begin{tabular}{|c|c|c|c|c|c|c|c|}
\hline & $\begin{array}{c}\text { Speed Limit } \\
\text { Difference } \\
\text { Equal to or } \\
\text { greater than } 10 \\
\text { mph? }\end{array}$ & $\begin{array}{l}\text { Average } \\
\text { Signal } \\
\text { Distance } \\
\text { (miles) }\end{array}$ & O Level & C Level & KAB Level & Level & $\begin{array}{l}\text { reducing } \\
\text { KAB Level }\end{array}$ \\
\hline US17A & $\begin{array}{l}\text { No } \\
\text { Yes }\end{array}$ & $\begin{array}{l}0.27 \\
0.27\end{array}$ & $\begin{array}{l}6.89 \% \\
3.87 \%\end{array}$ & $\begin{array}{l}-4.76 \% \\
-2.61 \%\end{array}$ & $\begin{array}{l}-2.13 \% \\
-1.25 \%\end{array}$ & $\begin{array}{l}4.17 \% \\
4.29 \%\end{array}$ & $\begin{array}{l}51.12 \% \\
29.11 \%\end{array}$ \\
\hline $\begin{array}{l}\text { Garlinto } \\
\text { n Rd }\end{array}$ & No & 0.36 & $5.58 \%$ & $-3.82 \%$ & $-1.76 \%$ & $1.55 \%$ & $113.23 \%$ \\
\hline N Lake & No & 0.55 & $2.38 \%$ & $-1.59 \%$ & $-0.79 \%$ & $5.43 \%$ & $14.54 \%$ \\
\hline Dr & Yes & 0.55 & $-1.01 \%$ & $0.66 \%$ & $0.35 \%$ & $4.40 \%$ & $-7.95 \%$ \\
\hline SC 642 & $\begin{array}{l}\text { No } \\
\text { Yes }\end{array}$ & $\begin{array}{l}0.52 \\
0.52\end{array}$ & $\begin{array}{l}3.05 \% \\
-0.45 \%\end{array}$ & $\begin{array}{l}-2.05 \% \\
0.30 \%\end{array}$ & $\begin{array}{l}-1.00 \% \\
0.16 \%\end{array}$ & $\begin{array}{l}6.40 \% \\
7.13 \%\end{array}$ & $\begin{array}{l}15.62 \% \\
-2.24 \%\end{array}$ \\
\hline US 52 & $\begin{array}{l}\text { No } \\
\text { Yes }\end{array}$ & $\begin{array}{l}0.31 \\
0.31\end{array}$ & $\begin{array}{l}6.31 \% \\
3.22 \%\end{array}$ & $\begin{array}{l}-4.35 \% \\
-2.16 \%\end{array}$ & $\begin{array}{l}-1.97 \% \\
-1.05 \%\end{array}$ & $\begin{array}{l}5.61 \% \\
6.47 \%\end{array}$ & $\begin{array}{l}35.09 \% \\
16.23 \%\end{array}$ \\
\hline US 17 & Yes & 0.61 & $-2.15 \%$ & $1.39 \%$ & $0.77 \%$ & $9.96 \%$ & $-7.73 \%$ \\
\hline
\end{tabular}

669

$\begin{array}{lll}670 & 5.3 \quad \text { Effects of other contributing factors on crash severity }\end{array}$

671 Note that, the coefficient of the angle variable is a random parameter that follows a random

672 distribution. As shown in Table 6, the mean of the coefficient (mean.Angle) associated with

673 angle is found to be positive and statistically significant in the ROP model. Its standard deviation

674 (S.D.Angle) is also found to be statistically significant, implying the existence of unobserved

675 heterogeneity across observations. The coefficient of the angle variable is estimated to follow a

676 uniform distribution with a mean of 0.330 and a standard deviation of 1.030. It is found that all 
677 observations have a positive coefficient associated with the angle crashes, suggesting an

678 association between angle crashes and higher crash severity.

679

680 As depicted by the marginal effects in Table 11, other contributing factors except for the peak

681 period are associated with higher crash severity levels (i.e., $\mathrm{C}$ and $\mathrm{KAB}$ ) while less likely to be a

682 lower crash severity (i.e., O). Crashes involving pedestrians will lead to higher crash severity

683 levels and increase the probability of KAB by $57.69 \%$. The presence of AADT over 30,000

684 vehicles/day results in a corresponding increase in the likelihood of C and KAB given the critical

685 role of high traffic volume in overall crashes at the signalized intersections. Not surprisingly, an

686 increase in the posted speed limit is associated with a greater likelihood of $\mathrm{C}$ and KAB. The

687 higher speed limit naturally results in a higher vehicle operational speed, with an increase in the

688 severity of crashes. The bad light condition (i.e., dark) of roadways is associated with a higher

689 likelihood of $\mathrm{C}$ and $\mathrm{KAB}$. The peak period leads to lower crash severity (i.e., O). During peak

690 periods, the traffic volume is relatively higher compared to off-peak periods, which would

691 contribute to lower average speeds of the vehicles during peak periods, thus resulting in reduced

692 crash severity. The crash, which is either rear-end or angle crash, is associated with higher

693 probability of $\mathrm{C}$ and $\mathrm{KAB}$.

694

695 Table 11 Marginal Effects of other Contributing Factors

\begin{tabular}{cccc}
\hline $\begin{array}{c}\text { Other Contributing } \\
\text { Factors }\end{array}$ & $\begin{array}{c}\text { Marginal Effect } \\
\text { for O }\end{array}$ & $\begin{array}{c}\text { Marginal Effect } \\
\text { for C }\end{array}$ & $\begin{array}{c}\text { Marginal Effect for } \\
\text { KAB }\end{array}$ \\
\hline Pedestrian & $-69.83 \%$ & $12.14 \%$ & $57.69 \%$ \\
AADT_over_30k & $-5.92 \%$ & $4.11 \%$ & $1.81 \%$
\end{tabular}




\begin{tabular}{cccc}
\hline $\begin{array}{c}\text { Other Contributing } \\
\text { Factors }\end{array}$ & $\begin{array}{c}\text { Marginal Effect } \\
\text { for O }\end{array}$ & $\begin{array}{c}\text { Marginal Effect } \\
\text { for C }\end{array}$ & $\begin{array}{c}\text { Marginal Effect for } \\
\text { KAB }\end{array}$ \\
\hline Speed_Limit & $-0.24 \%$ & $0.16 \%$ & $0.07 \%$ \\
Light & $-9.14 \%$ & $6.01 \%$ & $3.13 \%$ \\
Peak & $2.30 \%$ & $-1.59 \%$ & $-0.71 \%$ \\
Rear_end & $-3.47 \%$ & $2.38 \%$ & $1.09 \%$ \\
Angle & $-9.21 \%$ & $6.09 \%$ & $3.12 \%$ \\
\hline
\end{tabular}

696

\section{Conclusions}

698 This study has investigated the hierarchical effects of ASCS on the crash severity by developing 699 random-parameter ordered regression models with observed heterogeneity, which accounts for 700 both observed and unobserved heterogeneity. Crash data from six ASCS corridors with 65 701 signalized intersections are used to develop the models. Four different random-parameter ordered 702 regression models (two ordered probit models, and two ordered logit models) are established and 703 compared. It is found that the ROP and ROL models perform better than the RP and RL models 704 in terms of the AIC and the goodness of fit of the model. The ROP model outperforms the ROL 705 model in terms of classification model performance measures: accuracy, overall precision, and 706 overall recall. This study is unique as it demonstrates the existence of the hierarchical effects of 707 ASCS on the crash severity. The analyses reveal that the presence of ASCS is associated with 708 lower crash severity. Speed limit difference between major streets and minor streets at an 709 intersection (intersection feature) and average signal distance on a corridor (corridor feature) are

710 found to be capable of capturing the hierarchical effects of ASCS on the crash severity. Other 
711 variables related to intersection features such as the number of legs at an intersection and number

712 of through/left/right lanes at an intersection and corridor features such as average AADT on a

713 corridor are attempted in the model, but these variables are not statistically significant. Thus,

714 these variables are not able to capture the hierarchical effects of ASCS on the crash severity in

715 this study. In the future, variables related to zonal features such as population densities could be

716 accounted for to capture the hierarchical effects of ASCS on the crash severity. Other

717 contributing factors, such as annual average daily traffic, speed limit, lighting, crash type (rear-

718 end, angle), pedestrian involvements, are associated with higher crash severity. The peak period

719 leads to lower crash severity. Unobserved heterogeneity of the effect of angle crashes on crash

720 severity is found to exist across the observations by using the uniform distribution to explicitly

721 account for crash-specific variations in the effects of angle crashes.

722

723 To evaluate the performance of the ROP model on the high proportion of severe crash severity,

724 further studies on investigating the applicability of the model in the case of the high proportion

725 of severe crash severity may be carried out once a suitable case study is available.

726

727 Identifying the hierarchical effects of ASCS on the crash severity could help transportation

728 agencies achieve higher safety benefits by selecting ASCS deployment sites by considering

729 specific intersection and corridor features. The findings of this study have several practical

730 implications for establishing ASCS implementation guidelines from the standpoint of safety.

731 Two useful metrics, speed limit difference between a major street and a minor street at an

732 intersection (intersection feature) and average signal distance on a corridor (corridor feature),

733 could help transportation agencies to deploy ASCS appropriately. Two practical implications are 
734 found: 1) when speed limit difference between major streets and minor streets at an intersection

735 is equal to or greater than $10 \mathrm{mph}$, and the average signal distance on a corridor is less than the

736 threshold of 0.49 miles, the ASCS is more likely associated with lower crash severity; and 2)

737 when speed limit difference between major streets and minor streets at an intersection is less than

$73810 \mathrm{mph}$, and the average signal distance on a corridor is less than the threshold of 0.69 miles, the

739 ASCS is associated with lower crash severity. This finding is related to the particular type of

740 ASCS, and future studies may be conducted to include multiple types of ASCS.

742 Declarations of Interest: None.

\section{Acknowledgments}

744 The authors acknowledge the South Carolina Department of Transportation (SCDOT), which

745 provided funding (SCDOT Research Project: SPR 737) for this research. The authors also

746 sincerely acknowledge SCDOT SPR 737 Steering Committee for providing valuable guidance to

747 the authors. The contents of this paper reflect the views of the authors who are responsible for

748 the facts and the accuracy of the presented data. The contents do not reflect the official views of

749 SCDOT or FHWA. This paper does not constitute a standard, specification, or regulation.

\section{REFERENCE}

751 Antonucci, N.D., Hardy, K.K., Slack, K.L., Pfefer, R., Neuman, T.R., 2004. Guidance for

752 implementation of the AASHTO strategic highway safety plan. Volume 12: A Guide for

753 Reducing Collisions at Signalized Intersections, Transportation Research Board of the

$754 \quad$ National Academies, Washington, DC. 
Brant, R., 1990. Assessing proportionality in the proportional odds model for ordinal logistic regression. Biometrics 464 , 1171. doi:10.2307/2532457

Burnham, K.P., Anderson, D.R., 2004. Multimodel inference. Sociol. Methods Res. 332 , 261304. doi: $10.1177 / 0049124104268644$

Chen, Y., Persaud, B., 2014. Methodology to develop crash modification functions for road safety treatments with fully specified and hierarchical models. Accid. Anal. Prev. 70, 131139. doi:10.1016/j.aap.2014.03.012Dabbour, E., Easa, S., Haider, M., 2017. Using fixedparameter and random-parameter ordered regression models to identify significant factors that affect the severity of drivers' injuries in vehicle-train collisions. Accid. Anal. Prev. 107, 20-30. doi:10.1016/j.aap.2017.07.017

Dutta, U., Lynch, J., Dara, B., Bodke S., 2010, Safety evaluation of the SCATS control system, Rep. No. MIOH UTC TS22p1-2 2010-Final, Michigan Ohio University Transportation Center.

Eghtedari, A.G., 2006. Measuring benefits of adaptive traffic signal control: case study of Mill Plain Boulevard, Vancouver, Washington. Transp. Res. Board 85th Annu. Meet.

Elkins, S., Niehus, G., 2012. InSync adaptive traffic control system for the Veterans Memorial Hwy Corridor on Long Island, NY. New York State Dept. of Transportation.Eluru, N., Bagheri, M., Miranda-Moreno, L.F., Fu, L., 2012. A latent class modeling approach for identifying vehicle driver injury severity factors at highway-railway crossings. Accid. Anal. Prev. 47, 119-127. doi:10.1016/j.aap.2012.01.027

Fan, W., Kane, M.R., Haile, E., 2015. Analyzing severity of vehicle crashes at highway-rail grade crossings: multinomial logit modeling. J. Transp. Res. Forum. https://doi.org/10.22004/ag.econ.241825 
778 Fink, J., Kwigizile, V., Oh, J.-S., 2016. Quantifying the impact of adaptive traffic control

779 systems on crash frequency and severity: Evidence from Oakland County, Michigan. J.

$780 \quad$ Safety Res. 57, 1-7. doi:10.1016/j.jsr.2016.01.001

781 Fontaine, M.D., Ma, J., Hu, J., 2015, Evaluation of the Virginia Department of Transportation

782 adaptive signal control technology pilot project. Report. No. VCTIR 15-R24, Virginia

783 Center for Transportation Innovation and Research.

784 Gartner, N.H., Pooran, F.J., Andrews, C.M., 2002. Optimized policies for adaptive control

785 strategy in real-time traffic adaptive control systems: implementation and field testing.

786 Transp. Res. Rec. J. Transp. Res. Board 18111 , 148-156. doi:10.3141/1811-18

787 Greene, W.H., 2003. Econometric Analysis. Pearson Education India.

788 Greene, W.H., Hensher, D.A., 2010. Modeling Ordered Choices: A primer. Cambridge

$789 \quad$ University Press.

790 Hilbe, J.M., 2011. Negative Binomial Regression. Cambridge University Press.

791 Huang, H., Chin, H.C., Haque, M.M., 2008. Severity of driver injury and vehicle damage in 792 traffic crashes at intersections: a Bayesian hierarchical analysis. Accid. Anal. Prev. 401 ,

793 45-54. doi:10.1016/j.aap.2007.04.002

794 Iteris, 2020. Iteris ClearGuide [WWW Document]. URL https://scdot.iteris-clearguide.com/ $795 \quad$ (accessed 4.3.20).

796 Jalayer, M., Shabanpour, R., Pour-Rouholamin, M., Golshani, N., Zhou, H., 2018. Wrong-way

797 driving crashes: a random-parameters ordered probit analysis of injury severity. Accid.

$798 \quad$ Anal. Prev. 117, 128-135. doi:10.1016/j.aap.2018.04.019

799 Jin, W., Khan, S.M., Chowdhury, M., 2019. Exploring the safety effects of adaptive signal

$800 \quad$ control systems, in: International Conference on Transportation and Development 2019. 
Kergaye, C., Stevanovic, A., Martin, P., 2009. Comparison of before-after versus off-on adaptive traffic control evaluations. Transp. Res. Rec. J. Transp. Res. Board 2128, 192-201. doi: $10.3141 / 2128-20$

Khattak, Z.H., 2016. Evaluating the Operational and Safety Aspects of Adaptive Traffic Control

807

808

809

810 Systems in Pennsylvania. Univ. Pittsburgh Thesis.

Khattak, A., Tung, L.-W., 2015. Severity of pedestrian crashes at highway-rail grade crossings.

$$
\text { J. Transp. Res. Forum. https://doi.org/10.22004/ag.econ.241830 }
$$

Khattak, Z.H., Fontaine, M.D., Smith, B.L., Ma, J., 2019a. Crash severity effects of adaptive signal control technology: an empirical assessment with insights from Pennsylvania and Virginia. Accid. Anal. Prev. 124, 151-162. doi:10.1016/j.aap.2019.01.008

Khattak, Z.H., Magalotti, M.J., Fontaine, M.D., 2019b. Operational performance evaluation of adaptive traffic control systems: a Bayesian modeling approach using real-world $\{$ GPS $\}$ and private sector $\{$ PROBE $\}$ data. J. Intell. Transp. Syst. 242 , 156-170. doi:10.1080/15472450.2019.1614445

Khattak, Z.H., Magalotti, M.J., Fontaine, M.D., 2018. Estimating safety effects of adaptive signal control technology using the Empirical Bayes method. J. Safety Res. 64, 121-128. doi:10.1016/j.jsr.2017.12.016

Khazraee, S.H., Johnson, V., Lord, D., 2018. Bayesian Poisson hierarchical models for crash data analysis: investigating the impact of model choice on site-specific predictions. Accid. Anal. Prev. 117, 181-195. doi:10.1016/j.aap.2018.04.016

Krishnan, M.J., Anjana, S., Anjaneyulu, M.V.L.R., 2013. Development of hierarchical safety performance functions for urban mid-blocks. Procedia - Soc. Behav. Sci. 104, 1078-1087. 
825 Lowrie, P.R., 1990. Scats, sydney co-ordinated adaptive traffic system: A traffic responsive 826 method of controlling urban traffic.

827 Ma, J., Fontaine, M.D., Zhou, F., Hu, J., Hale, D.K., Clements, M.O., 2016. Estimation of crash 828 modification factors for an adaptive traffic-signal control system. J. Transp. Eng. 14212 , 829 4016061. doi:10.1061/(asce)te.1943-5436.0000890

830 National Research Council (US)., 2010. Highway Safety Manual. AASHTO.

831 O’brien, R.M., 2007. A caution regarding rules of thumb for variance inflation factors. Qual.

832 Quant. 41 5 , 673-690. doi:10.1007/s11135-006-9018-6

833 Rahman, M.S., Abdel-Aty, M., Lee, J., Rahman, M.H., 2019. Safety benefits of arterials' crash 834 risk under connected and automated vehicles. Transp. Res. Part C Emerg. Technol. 100, 354-371. doi:10.1016/j.trc.2019.01.029

836 Sammut Claudeand and Webb, G.I. (Ed.), 2010. Accuracy, in: Encyclopedia of Machine Learning. Springer US, Boston, MA, pp. 9-10. doi:10.1007/978-0-387-30164-8_3

838 Sarrias, M., 2016. Discrete choice models with random parameters in R: The Rchoice Package. J. 839 Stat. Softw. 74 10 . doi:10.18637/jss.v074.i10

840 SCDOT, 2020a. South Carolina Traffic Collision Report Form (TR-310) and Supplement Truck 841 and Bus Report Form Instruction Manual [WWW Document]. URL https://scdps.sc.gov/sites/default/files/Documents/forms/TR-310 Report Manual Revised

844 SCDOT, 2020b. GIS/Mapping [WWW Document]. URL https://www.scdot.org/travel/travel845 mappinggis.aspx (accessed 2.17.20).

846 So, J., Stevanovic, A., Posadas, E., Awwad, R., 2014. Field evaluation of a SynchroGreen 
adaptive signal system, in: T\&amp;DI Congress 2014. American Society of Civil

Ting, K.M., 2010. Precision and recall, in: Sammut Claudeand and Webb, G.I. (Ed.),

850 Encyclopedia of Machine Learning. Springer US, Boston, MA, p. 781. doi:10.1007/978-0-

$851 \quad 387-30164-8+652$

852 Van Asch, V., 2013. Macro-and micro-averaged evaluation measures [[basic draft]]. Belgium:

$853 \quad$ CLiPS 49.

854 Washington, S., Karlaftis, M.G., Mannering, F., Anastasopoulos, P., 2020. Statistical and

855 Econometric Methods for Transportation Data Analysis. CRC press.

856 Xie, K., Wang, X., Huang, H., Chen, X., 2013. Corridor-level signalized intersection safety

857 analysis in Shanghai, China using Bayesian hierarchical models. Accid. Anal. Prev. 50, 25-

$858 \quad 33$. doi:10.1016/j.aap.2012.10.003

859 Xie, K., Yang, D., Ozbay, K., Yang, H., 2019. Use of real-world connected vehicle data in

860 identifying high-risk locations based on a new surrogate safety measure. Accid. Anal. Prev.

$861 \quad$ 125, 311-319. doi:10.1016/j.aap.2018.07.002

862 Ye, F., Lord, D., 2014. Comparing three commonly used crash severity models on sample size

863 requirements: multinomial logit, ordered probit and mixed logit models. Anal. Methods

864 Accid. Res. 1, 72-85. doi:10.1016/j.amar.2013.03.001

865 Zhao, S., Khattak, A., 2015. Motor vehicle drivers' injuries in train-motor vehicle crashes.

866 Accid. Anal. Prev. 74, 162-168. doi:10.1016/j.aap.2014.10.022

867 